\title{
Impact of Infrastructure Service Quality on Residents' Satisfaction in the United Arab Emirates (UAE), the Case of Ajman Emirate
}

\author{
Hajar Al Hubaishi, Abdelrahim Ali \\ Ajman Statistics and Competitiveness Center, Ajman, United Arab Emirates \\ Email: aaastudies@yahoo.com, hsaeed@ajman.ae
}

How to cite this paper: Al Hubaishi, H., \& Ali, A. (2021). Impact of Infrastructure Service Quality on Residents' Satisfaction in the United Arab Emirates (UAE), the Case of Ajman Emirate. Open Journal of Business and Management, 9, 2879-2893.

https://doi.org/10.4236/ojbm.2021.96161

Received: September 6, 2021

Accepted: November 12, 2021

Published: November 15, 2021

Copyright $\odot 2021$ by author(s) and Scientific Research Publishing Inc. This work is licensed under the Creative Commons Attribution International License (CC BY 4.0).

http://creativecommons.org/licenses/by/4.0/

\begin{abstract}
This paper discusses the results of a field survey conducted by Ajman Statistics and Competitiveness Center, to assess the level of Ajman residents' satisfaction on the availed infrastructure. A sample of 1032 households, was randomly selected from a total of 95,531 Households, residing in the emirate of Ajman and has prior experience in utilizing the availed infrastructure. Data were analyzed using the Statistical Package for the Social Sciences (SPSS) version 22 and AMOS version 22. Structural Equation Modeling (SEM) analysis showed an acceptable model fit used to measure residents' satisfaction. Findings showed that accessibility, safety, and empathy dimensions correlated positively with residents' satisfaction, while reliability and responsiveness dimensions didn't suggest direct relationship with residents' satisfaction. Generally, $90 \%$ of Ajman residents were satisfied with infrastructure. Safety dimension had the highest proportion of satisfaction among residents, about $93 \%$, while the accessibility dimension had the lowest satisfaction with only $88 \%$. The findings of this study are expected to support the concerned decision-makers in improving infrastructure within the emirate of Ajman.
\end{abstract}

\section{Keywords}

UAE, Ajman Emirate, Infrastructure, Residents' Satisfaction, Dimensions

\section{Introduction}

\subsection{Forward}

This introduction identifies factors that influence infrastructure components and their relation to residents' satisfaction. Specifically, it presents an overview, 
outlines the research framework, identifies the research objectives, defines the research questions, specifies the research null hypotheses, designates the research scope and determines the importance of the research.

\subsection{Overview}

Oswald et al. (2011) defined Infrastructure as the the foundation for economic growth and productivity. Likewise, Buhr (2003) defined it as the earning asset, that produces services, such as, electricity, water, waste, parks, transportation, road networks, telecommunication, hospitals, and education etc. However, it was identified by Davos World Economic Forum in 2019, as the second pillar for the Global Competitiveness Index (GCI), which comprises roads, air transport, rail and sea transport, electricity access and supply, and drinking water supply. It is also one of the basic factors that strengthens and enhances the economic growth and human development process. Likewise, Aliu Momoh (2018), argued that, "Infrastructures are generally thought of as those facilities owned by government or by private regulated utilities, that are used in the delivery of either public goods or the production of services". Moreover, the American Society of Civil Engineers (2017) listed the infrastructure as: aviation, bridges, dams, drinking water, energy, hazardous waste, inland waterways, levees, parks, recreation, ports, rail, roads, schools, solid waste, transit, wastewater. Similarly, OECD in 2004, listed water distribution, power generation \& distribution, gas production \& distribution, roads \& railways, and telecommunications as infrastructure.

Ajman government is seeking to gain residents' satisfaction on infrastructure, which could only be attained through improved policies regarding managing and maintaining the infrastructure. Currently, the infrastructure components such as local roads and bridges, public parks, playground, wastewater or sewer system, solid waste, landfills, drainage and seawalls, dikes and ports, are all under the local government jurisdiction, whereas, the rest such as electricity and water supply are under federal government jurisdiction.

Moreover, telecommunication services are provided by Etisalat and DU, healthcare is under the Ministry of Health, Schools are under the Ministry of Education, and Transportation is under several entities such as Ajman transport Authority. It is noteworthy that, the local government of Ajman, has no control over those services which are under federal government.

\subsection{Research Objectives}

The research objectives of this study comprise:

- Determining the factors influencing the infrastructure provided within $\mathrm{Aj}$ man Emirate.

- Gaining deep insight into the influence of factors identified in the study in accordance with residents' perceptions.

- Measuring residents' satisfaction level on infrastructure. 


\subsection{Research Questions}

- What factors influence residents' satisfaction on infrastructure in Ajman Emirate?

- What is the resident's satisfaction level on the availed infrastructure?

\subsection{Research Hypotheses}

The research hypotheses are based on the above-mentioned research objective and research question. These hypotheses are set up to assess the direction and magnitude of the correlation between the quality dimensions of accessibility, safety, reliability responsiveness, empathy, and the residents' satisfaction. This assessment was verified using the structural model, which is part of the SEM model, to show and express the relationships and correlational links among the latent variables, regarding residents' satisfaction on the availed infrastructure, as follow:

H1: Accessibility correlates positively with residents' satisfaction on infrastructure.

$\mathrm{H} 2$ : Safety correlates positively with residents' satisfaction on infrastructure.

H3: Reliability correlates positively with residents' satisfaction on infrastructure.

H4: Responsiveness correlates positively with residents' satisfaction on infrastructure.

H5: Empathy correlates positively with residents' satisfaction on infrastructure.

\subsection{Research Scope}

The scope of this study is to measure residents' satisfaction on infrastructure, to identify and gain deep insight into evaluations regarding factors that influence infrastructure and residents' satisfaction and their relationship. A conceptual model that describes interactions among all factors was developed. This study targeted residents of Ajman emirate, who used availed infrastructure. Based on the statistical poll made available by Ajman Census in 2017, about 95,531 households were residing in the Emirate of Ajman. Because of the population homogeneity, a stochastic sample size of $2.2 \%$, was considered appropriate to represent the households' population, which is equivalent to 2085 households.

\subsection{Significance of the Study}

The significance of this study, could be categorized into two, namely theoretical and practical, as follows:

\section{Theoretical significance of the study:}

- The design adopted the comprehensive approach, where the household was the primary unit for data collection on satisfaction with regard to several services provided in the Emirate of Ajman, where households reported using more than one service can be linked such that level of satisfaction with regard 
to clusters of services can be analyzed. Despite that, this approach incurs multiplied efforts of design, implementation, and quality control measures. The value added through linking multiple services, by far, exceeds the vertical approach through dealing with each type of services as stand alone.

- It provides a deep understanding of infrastructure numerous factors influencing service delivery and its impact on residents' satisfaction.

- It provides insights on how local government plan on capacity building to endure reforms and create a sustainable institution (Kunicova, 2018).

- It provides better understanding of the citizens' needs, creating a structured policy that will support the accomplishment of government objectives in terms of providing the services through the available infrastructure in the Emirate of Ajman.

\section{Practical significance of the study:}

- It established a reliable future baseline and documentation for satisfaction studies on infrastructure.

- It enables concerned decision makers, to identify priority areas for improvement, using residents' perspective and focus all efforts on enhanced infrastructure in the Emirate of Ajman.

- A successful community will be achieved through infrastructure that will enable the economy to prosper.

\section{Literature Review}

\subsection{Introduction}

Infrastructure was best defined by Hirsshhausen (1966), as "the sum of material, institutional and personal facilities and data which are available to the economic agents, and which contribute to realizing the equalization of the remuneration of comparable inputs, in the case of a suitable allocation of resources, that is complete integration and maximum level of economic activities." The word "infra" is rooted from the Latin language, which means "below," which can be interpreted as "foundation," according to Buhr (2003). The World Bank (2005) described infrastructure as a "means for ensuring the delivery of goods and services that promote prosperity and growth and contribute to the quality of life, including the social well-being, health and safety of citizens, and the quality of their environments.

Oswald et al. (2011) stated that infrastructure is defined as all facilities used to deliver energy, water and sanitation, telecommunication, and transport services. Aliu Momoh (2018) described the word "infrastructure" as structural elements of an economy that facilitate the flow of goods and services between buyers and sellers, came into current use in the 1950s, when the military applied it to their permanent installation. In fact, "infrastructure" has been used earlier pertaining to military installation purposes. However, as time evolves, the term "infrastructure" is now more associated with economic growth. A modern general usage of the term concerns the necessary economic and organizational founda- 
tion of a highly developed economy (transport network, labor force, etc.), Buhr (2003).

According to Hirsshhausen (1966) in a more realistic sense, infrastructure is:

- The totality of all earning assets, equipment and circulating capital in an economy, that serve energy provision, transport service, and telecommunications.

- Structures, for the conservation of natural resources and transport routes in the broadest sense.

- Buildings and installations of public administration, education, research, healthcare, and social welfare.

Buhr (2003) and Torrisi (2009), defined Infrastructure as an ambiguous word that depends on how it will be used especially in classifying and maintaining it. However, Infrastructures are generally thought of as those facilities owned by government or by private, regulated utilities that are used in the delivery of either public goods or the production of services. The ASCE (2017), listed the infrastructure report card of 2017, as: aviation, bridges, dams, drinking water, energy, hazardous waste, inland waterways, levees, parks and recreation, ports, rail, roads, schools, solid waste, transit, wastewater, while OECD (2004) has listed water distribution, power generation $\&$ distribution, gas production $\&$ distribution, roads \& railways, and telecommunications as infrastructure.

\subsection{Infrastructure Dimensions}

They comprise the following:

- Accessibility: means the presence or availability of infrastructure which residents can access.

- Safety: means infrastructure is in good physical condition and are safe to use.

- Reliability: pertains to the effectiveness of maintenance of infrastructure, value for money, planning, and design of public spaces (streets, boulevards, and shopping area), and variability on travel time.

- Responsiveness: refers to the speed in rectifying maintenance issues and meeting the current and future demands on infrastructure.

- Empathy: refers to the competence and expertise of people responsible for maintaining and resolving problems and complaints related to infrastructure.

It is noteworthy that, studies regarding citizens' satisfaction on infrastructure are not common, as only few countries carried out such satisfaction studies. Such satisfaction studies usually deal with access to infrastructure including a well-conditioned road, highway roads and adequacy of main roads and bridges, availability of drainage, rain control network and seawalls/dikes, location of solid waste/landfill, and wastewater/sewer network. Components of citizens satisfaction on infrastructure also include accessibility as well as access to the electric power distribution system and water supply. Safety was one of the qualities that satisfied the residents, in the 2018 residents satisfaction study of Ajman, which showed that safety having elements such as infrastructure's physical con- 
dition and footpath safety for pedestrians, and infrastructure safety are determinants of residents' satisfaction. According to Esfahani (2005), maintenance of public infrastructure especially on electricity, water, sanitation, transport, telecom, and the value for money of these paid utilities, makes the consumer satisfied. As for road congestion, residents are more satisfied with the reliability of travel time.

Overall, infrastructure arrangement and its design are reliable if there is regular maintenance. Responsiveness and empathy are often related to those who maintain the infrastructure, as the demand increase, so the capacity to handle the demand increases. Another component of responsiveness is the speed to respond to the infrastructure maintenance. According to Bitre (2017), the way problems and complaints are resolved, and the competence and expertise of people maintaining the infrastructure satisfy residents.

\section{Research Methodology}

\subsection{Introduction}

The process followed in conducting Ajman residents' satisfaction study contained the following elements:

- Research questions-sampling technique.

- Designing the Questionnaire-data collection.

- Data analysis.

\subsubsection{Research Questions}

This paper addressed the following questions:

1) Do the infrastructure service dimensions (accessibility, safety, reliability, responsiveness, and empathy) correlate positively with residents' satisfaction?

2) What is the residents' satisfaction level on availed infrastructure?

\subsubsection{Sampling Technique}

The Emirate of Ajman has a total of 95,531 households, according to the last 2017 Census. A sample of $2.2 \%$ households was randomly selected, to represent groups of different social class, occupation, and income strata and geographic proximity to government presence, giving them equal chance to participate in the study, with a $5 \%$ margin of error at a $95 \%$ confidence level. The sample targeted, comprised those 18 years of age and above, who have prior experience of availing the infrastructure.

\subsubsection{Designing the Questionnaire}

The study was conducted face-to-face via CAPI (Computer Assisted Personal Interview) methodology through a structured questionnaire. The questionnaires are available in an electronic system and could be accessed via KIG-SMS device, connected to internet service with a specific username and password, capturing respondents' location and matching targeted areas within Emirate of Ajman.

The questionnaire design principal, followed the following steps: 
- Identifying the survey aims and the goal of the questionnaire.

- Defining the target respondents.

- Developing the question type.

- Designing the question sequence and their overall layout, as pre-screening questions, screening Questions, respondent demographics questions, available Infrastructure questions, infrastructure Satisfaction Questions, suggestion, and improvement questions.

\subsubsection{Data Collection}

The data were collected through face-to-face interviews, using a standardized electronic questionnaire, accessed through tested and verified KIG-SMS device. A team of technical support was available throughout the process of data collection to ensure the integrity of data during fieldwork

The form was a built-in system and was designed to prevent mistakes and enable the enumerators to completely fill the form without missing any steps. This means that the system will only accept the submission of the filled form once all mandatory fields were answered; else, it will be highlighted in red, and the system will not proceed.

Data collected during this stage, were spontaneously checked, verified, and transmitted at a central database, protected, and accessed by authorized personnel only. All activities are logged in the system; the enumerator's activities were monitored every day. History and records are kept for further references.

\section{Data Analysis}

Data were analyzed using the SPSS version 22 and AMOS version 22. SPSS was used to assess respondents' profiles, and test reliability and validity, whereas AMOS was used to conduct SEM analysis. The Primary Sampling Units (PSUs) were selected on random probability bases that ensure the proportional representation method (probability proportionate to size/PPS).

\section{Research Findings}

\subsection{Introduction}

The study findings would be presented in the following order:

- Sample profile descriptions-reliability analyses.

- SEM analysis-summary of findings.

\section{Sample Profile Descriptions}

\section{a) Sample Interviewed}

The total number of households identified and visited was 2085 households, out of which 527 households did not respond, or $25 \%$. The rest of the sample, which is 1558 households or equivalent to about $75 \%$ of the total sample, responded. Out of 1558 households, 512 households or 33\%, were not interested in being interviewed. In addition, two households or .1\% did not pass the eligibility screening test. Hence, 1062 or $68 \%$ households were interviewed, which repre- 
sents the response rate. Quality control and validation and checking off completed interviews led to the exclusion of 30 or $3 \%$ completed interviews. Consequently, the final number of completed and verified interviews was 1032 households.

b) Sample Awareness Level and Availed Infrastructure (Table 1, Table 2)

Table 1. Residents' awareness level on infrastructure.

\begin{tabular}{|c|c|c|}
\hline \multirow{2}{*}{ Infrastructure } & \multicolumn{2}{|c|}{ Emirate of Ajman } \\
\hline & $\mathrm{n}$ & $\%$ \\
\hline Local roads and bridges & 846 & $82 \%$ \\
\hline Electric power distribution system & 908 & $88 \%$ \\
\hline Water supply system & 896 & $87 \%$ \\
\hline Public Parks/playground \& entertainment & 822 & $80 \%$ \\
\hline Port & 511 & $50 \%$ \\
\hline Waste Water/sewer system & 762 & $74 \%$ \\
\hline Drainage, rain control and Seawalls/dikes & 517 & $50 \%$ \\
\hline Solid waste/Landfill & 511 & $50 \%$ \\
\hline School buildings and facilities ${ }^{\star}$ (Govt) & 675 & $65 \%$ \\
\hline School buildings and facilities ${ }^{\star}$ (Private) & 646 & $63 \%$ \\
\hline Health care buildings and facilities ${ }^{\star}$ (Govt) & 752 & $73 \%$ \\
\hline Health care buildings and facilities ${ }^{\star}$ (Private) & 747 & $72 \%$ \\
\hline Telecommunication network (fixed line and Mobile telephony, Data, broadband, cable TV) * & 734 & $71 \%$ \\
\hline Transportation network (roadway segment, transit terminals, harbors) * & 627 & $61 \%$ \\
\hline
\end{tabular}

Table 2. Residents' availed infrastructure.

\begin{tabular}{|c|c|c|}
\hline \multirow{2}{*}{ Infrastructure } & \multicolumn{2}{|c|}{ Emirate of Ajman } \\
\hline & $\mathrm{n}$ & $\%$ \\
\hline Local roads and bridges & 679 & $66 \%$ \\
\hline Electric power distribution system & 801 & $78 \%$ \\
\hline Water supply system & 755 & $73 \%$ \\
\hline Public Parks/playground \& entertainment & 691 & $67 \%$ \\
\hline Port & 131 & $13 \%$ \\
\hline Waste Water/sewer system & 529 & $51 \%$ \\
\hline Drainage, rain control and Seawalls/dikes & 185 & $18 \%$ \\
\hline Solid waste/Landfill & 188 & $18 \%$ \\
\hline School buildings and facilities ${ }^{\star}$ (Govt) & 384 & $37 \%$ \\
\hline School buildings and facilities ${ }^{\star}$ (Private) & 404 & $39 \%$ \\
\hline Health care buildings and facilities ${ }^{\star}$ (Govt) & 525 & $51 \%$ \\
\hline Health care buildings and facilities ${ }^{\star}$ (Private) & 612 & $59 \%$ \\
\hline Telecommunication network (fixed line and Mobile telephony, Data, broadband, cable TV) * & 619 & $60 \%$ \\
\hline Transportation network (roadway segment, transit terminals, harbors) * & 443 & $43 \%$ \\
\hline
\end{tabular}




\section{Analysis of Reliability}

\subsection{Reliability Measurement}

Any research based on measurement must be concerned with the accuracy or dependability or, as we usually call it, reliability of measurement (Cronbach, 1951). The purpose of evaluating the internal reliability of the questionnaire is to test the reliability of the dimensions used to measure each construct, with Cronbach's alpha test. The test results using SPSS 22, indicated that all item values were $>.600$ and were reliable to measure each construct (Hair Jr et al., 2015). In Table 3, Cronbach's alpha coefficient results presented for each dimension for infrastructure questions found between .823 and .900 , which are on acceptable levels; questions for each dimension measured the same dimension, and thus the internal consistencies of the measures are verified.

\subsection{Structural Equation Modeling (SEM)}

\section{SEM Model and Solution Procedure}

Infrastructure latent construct was measured using accessibility, safety, reliability, responsiveness, and empathy. A set of data collected according to the response of respondents. The structural relationships between variables displayed in Figure 1. Hereafter, the structural equation modeling model (SEM) performed by employing AMOS 22 software to notice the relationship between infrastructure dimensions (accessibility, safety, reliability, responsiveness, and empathy) with residents' satisfaction (related to 24 elements). SEM is an appropriate analytical technique for testing the relationship between theoretical constructs and visualized through path diagrams (Bechger et al., 1999). The model validation, then evaluated through convergent, discriminant validity, and reliability.

\section{Results}

\subsection{Fit Analysis}

The result in Table 4 shows results of the fit analysis and indicated that:

RMR of .032 (valid), GFI is .877 (valid), NFI is .90 (valid), IFI is .918 (valid), CFI is .918 (valid) for infrastructure.

\section{In overall, the model has met the criteria.}

Table 3. Results of reliability.

\begin{tabular}{ccc}
\hline Construct & Number of Questions & Cronbach's Alpha \\
\hline Accessibility & 9 & .823 \\
Responsiveness & 2 & .900 \\
Safety & 3 & .865 \\
Reliability & 5 & .827 \\
Empathy & 2 & .885 \\
\hline
\end{tabular}




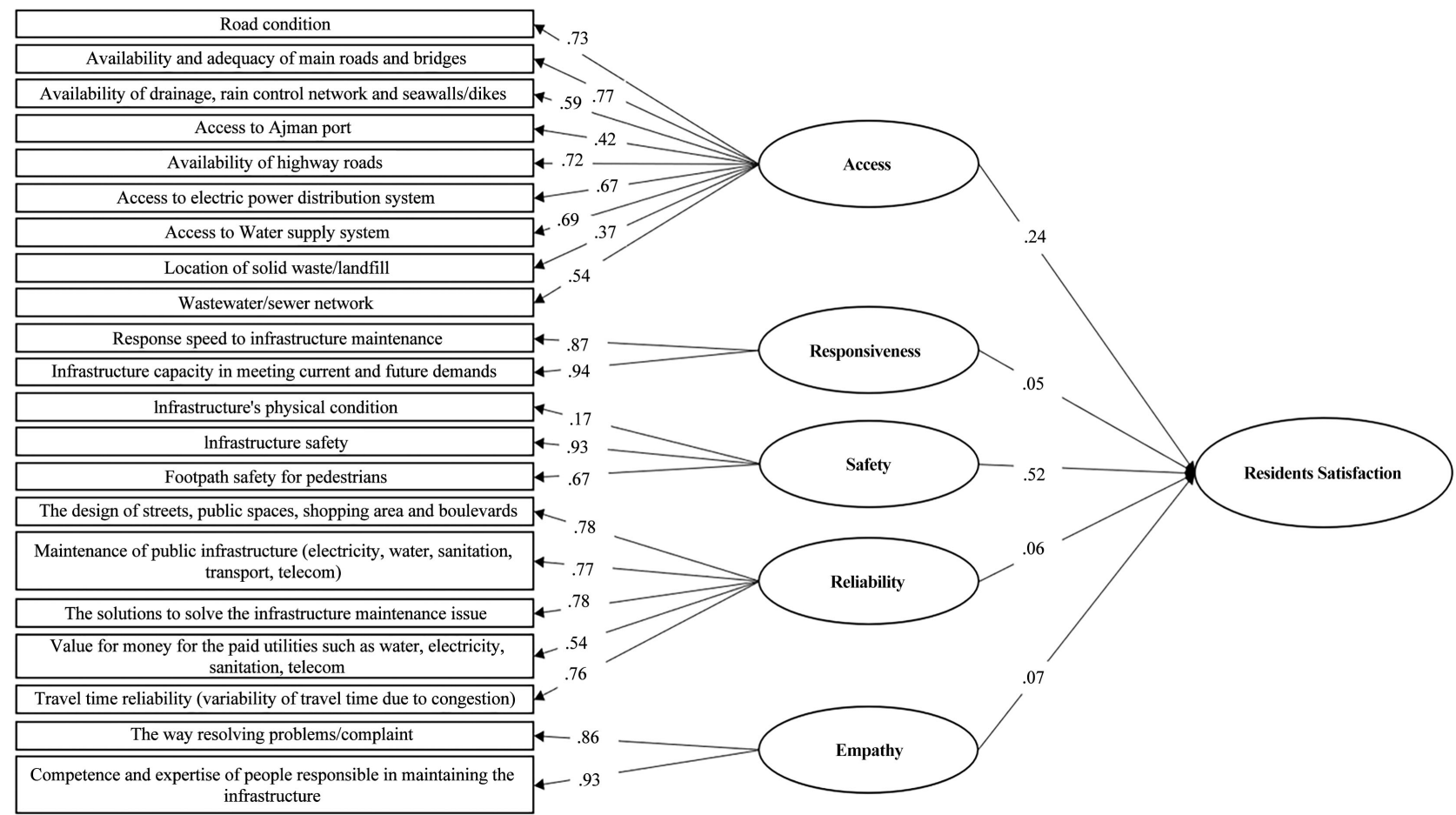

Figure 1. Path diagram for structural model.

Table 4. Model fit indicators.

\begin{tabular}{|c|c|c|c|c|c|}
\hline Model & RMR & & GFI & AGFI & PGFI \\
\hline Infrastructure model & .032 & & .877 & .845 & .693 \\
\hline \multirow{2}{*}{ Model } & NFI & RFI & IFI & TLI & \multirow{2}{*}{ CFI } \\
\hline & Delta1 & rho1 & Delta2 & rho2 & \\
\hline Infrastructure model & .906 & .890 & .918 & .905 & .918 \\
\hline
\end{tabular}

\subsection{Measurement Equation: Infrastructure}

Infrastructure variable estimates showed the following:

- The main element of accessibility, was availability and adequacy of main roads and bridges (.774).

- The main element of safety, was Infrastructure's safety (.927).

- The main element of reliability was the maintenance of public infrastructure (electricity, water, sanitation, transport, telecom) (.784).

- The main element of responsiveness was infrastructure capacity in meeting current and future demands (.943).

- The main element of empathy was the expertise of people responsible for maintaining the infrastructure (.93).

All significant dimensions affect each variable with alpha .001 .

\subsection{Assessment of Structure Model and Hypothesis Testing}

Assessment of structure model and hypothesis are shown in Table 5 for infra- 
structure, as follows:

H1: Accessibility correlates positively with residents satisfaction on infrastructure.

The probability of getting a critical ratio as large as 5.139 in absolute value is less than .001. In other words, the regression weight for AC in the prediction of SAT is significantly different from zero at the .001 level (two-tailed). This means that this hypothesis is supported and has enough evidence to indicate that accessibility has influence on residents' satisfaction on Infrastructure service.

H2: Safety correlates positively with residents' satisfaction on infrastructure.

The probability of getting a critical ratio as large as 12.395 in absolute value is less than .001. In other words, the regression weight for ST in the prediction of SAT is significantly different from zero at the .001 level (two-tailed). This means that this hypothesis is supported and has enough evidence to indicate that safety has influence on resident's satisfaction on Infrastructure service.

H3: Reliability correlates positively with residents' satisfaction on infrastructure.

The probability of getting a critical ratio as large as 1.431 in absolute value is .152. In other words, the regression weight for RL in the prediction of SAT is not significantly different from zero at the .05 level (two-tailed). This means that this hypothesis is not supported and has no sufficient evidence to indicate that reliability influences residents' satisfaction on infrastructure.

H4: Responsiveness correlates positively with residents satisfaction on infrastructure.

The probability of getting a critical ratio as large as 1.432 in absolute value is .152. In other words, the regression weight for RS in the prediction of SAT is not significantly different from zero at the .05 level (two-tailed). This means that this hypothesis is not supported and has no sufficient evidence to indicate that responsiveness has influence on resident's satisfaction on Infrastructure service.

H5: Empathy correlates positively with residents' satisfaction on infrastructure.

Table 5. Assessment structure model of infrastructure.

\begin{tabular}{|c|c|c|c|c|c|c|}
\hline \multicolumn{3}{|c|}{ Construct } & \multirow{2}{*}{$\begin{array}{c}\text { Estimate } \\
.295\end{array}$} & \multirow{2}{*}{$\begin{array}{c}\text { Standardized } \\
\text { Loadings } \\
.236^{* * *}\end{array}$} & \multirow{2}{*}{$\begin{array}{l}\text { S.E. } \\
.057\end{array}$} & \multirow{2}{*}{$\begin{array}{l}\text { C.R. } \\
5.139\end{array}$} \\
\hline Accessibility & $\rightarrow$ & SF (Satisfaction) & & & & \\
\hline Safety & $\rightarrow$ & SF (Satisfaction) & .729 & $.517^{\star \star \star}$ & .059 & 12.395 \\
\hline Reliability & $\rightarrow$ & SF (Satisfaction) & .073 & .064 & .051 & 1.431 \\
\hline Responsiveness & $\rightarrow$ & SF (Satisfaction) & .039 & .047 & .027 & 1.432 \\
\hline Empathy & $\rightarrow$ & SF (Satisfaction) & .063 & .072 & .025 & 2.53 \\
\hline
\end{tabular}

${ }^{\star},{ }^{* *},{ }^{* *}$ Significant at alpha. $.05, .01, .001$ respectively; S.E: Standard Error. 
The probability of getting a critical ratio as large as 2.53 in absolute value is .011. In other words, the regression weight for EM in the prediction of SAT is significantly different from zero at the .05 level (two-tailed). This means that this hypothesis is supported and has enough evidence to indicate that empathy influences residents' satisfaction on infrastructure.

\subsection{Residents' Satisfaction Results}

\section{Resident's Overall Satisfaction on Infrastructure}

Results in Table 6 present the residents' overall satisfaction of compiled dimensions of Infrastructure. The dimensions were accessability, responsiveness, safety, reliability, and empathy.

On average, about $39 \%$ of respondents were very satisfied with the infrastructure, while on the other end, only $1 \%$. were very dissatisfied.

Among the dimensions, safety has the most very satisfied respondents with $44 \%$. Followed by accessability to infrastructure with $40 \%$ very satisfied respondents. The rest ranged about $36 \%$ to $38 \%$ very satisfied respondents.

In contrast, very dissatisfied respondents reached about $2 \%$ on accessability dimension, while the rest of the dimensions has $1 \%$ and below proportion of very dissatisfied respondents.

Generally, almost $90 \%$ of the respondents were either satisfied or very satisfied with the Infrastructure in the Emirate of Ajman. While about 3\% were dissatisfied or very dissatisfied, and $8 \%$ were undecided.

Among the elements, safety has the highest proportion of satisfied or very satisfied respondents with about $93 \%$. Followed by empathy dimension with about $92 \%$ of either satisfied or very satisfied respondents. Responsiveness has about $90 \%$ of either satisfied or very satisfied respondents and reliability dimension has $89 \%$. The least among the dimensions is accessability with $88 \%$ of either satisfied or very satisfied respondents.

On the contrary, accessability dimension has the highest dissatisfied or very dissatisfied respondents with about $5 \%$. Followed by reliability dimension with about $4 \%$ dissatisfied or very dissatisfied respondents. The rest of the dimensions has $2 \%$ dissatisfied or very dissatisfied respondents. Undecided respondents were noted highest on responsiveness dimension with $8 \%$, while both reliability and accessability dimensions has $7 \%$ undecided each.

\section{Discussion}

This paper evaluated the factors that influence residents' satisfaction on infrastructure in the Emirate of Ajman, using research questions and hypotheses. Results identified five possible determinants, that influence residents' satisfaction on infrastructure, namely, accessibility, safety, reliability, responsiveness, and empathy. The study hypothesizes that these factors have a relationship with the residents' satisfaction on infrastructure. 
Table 6. Residents' overall satisfaction on infrastructure.

\begin{tabular}{|c|c|c|c|c|c|c|}
\hline Dimensions & Very Dissatisfied & Dissatisfied & Neutral & Satisfied & Very Satisfied & Total \\
\hline Access & $2 \%$ & $3 \%$ & $7 \%$ & $48 \%$ & $40 \%$ & 100 \\
\hline Responsiveness & $1 \%$ & $1 \%$ & $8 \%$ & $54 \%$ & $36 \%$ & 100 \\
\hline Safety & $1 \%$ & $1 \%$ & $5 \%$ & $49 \%$ & $44 \%$ & 100 \\
\hline Reliability & $1 \%$ & $2 \%$ & $7 \%$ & $51 \%$ & $38 \%$ & 100 \\
\hline Empathy & $1 \%$ & $1 \%$ & $6 \%$ & $55 \%$ & $37 \%$ & 100 \\
\hline Average & $1 \%$ & $2 \%$ & $7 \%$ & $51 \%$ & $39 \%$ & 100 \\
\hline
\end{tabular}

Table 7. Infrastructure hypothesis $\mathrm{H} 1$ to $\mathrm{H} 5$.

\begin{tabular}{lll}
\hline Research Question & Research Hypotheses & \multicolumn{1}{c}{ Results } \\
\hline & $\begin{array}{l}\text { H1: Accessibility correlates positively with residents' } \\
\text { satisfaction on infrastructure. }\end{array}$ & Supported \\
& H2: Safety correlates positively with residents' & Supported \\
$\begin{array}{l}\text { What factors } \\
\text { influence residents } \\
\text { satisfaction on }\end{array}$ & $\begin{array}{l}\text { H3: Reliability correlates positively with residents' } \\
\text { infrastructure in } \\
\text { she Emirate of }\end{array}$ & $\begin{array}{l}\text { Natisfaction on infrastructure. } \\
\text { Ajman? }\end{array}$ \\
& $\begin{array}{l}\text { H4: Responsiveness correlates positively with } \\
\text { residents' satisfaction on infrastructure. }\end{array}$ & Not Supported \\
& $\begin{array}{l}\text { H5: Empathy correlates positively with residents' } \\
\text { satisfaction on infrastructure. }\end{array}$ & Supported \\
\hline
\end{tabular}

Based on the results, three hypotheses out of five, were fully supported. The research questions and corresponding hypotheses and results are summarized in Table 7.

\section{Conclusion}

Structural Equation Modeling (SEM) analysis showed an acceptable model fit, used to measure residents' satisfaction, as depicted by the following:

RMR of .032 (valid), GFI is .877 (valid), NFI is .90 (valid), IFI is .918 (valid), CFI is .918 (valid) for infrastructure.

The above results show that the model has met the criteria.

The final results showed that the hypotheses that, accessibility, safety, and empathy, correlate positively with residents' satisfaction on infrastructure, are supported and have enough evidence to indicate that, they have influence on residents' satisfaction on Infrastructure service.

Conversely, the two hypotheses that reliability and responsiveness correlate positively with residents's satisfaction on infrastructure, are not supported and have not enough evidence to indicate they have influence on residents' satisfaction on Infrastructure service.

The most utilized infrastructure in the Emirate of Ajman was electric power 
and water supply. It is noteworthy that, some of the rendered services were under the federal authorities, others under local government. Those under the federal authority comprised electricity and water supply, telecommunication, healthcare, schools, and transportation.

On the other hand, majority of respondents believed that their decision to stay in Ajman would be influenced by local roads and bridges, electric power distribution system, water supply system. More than half of respondents believed that their future decision to stay in Ajman would be influenced by local roads and bridges.

The analysis showed that availability and adequacy of main roads and bridges, had the greatest influence on accessibility dimension. Infrastructure safety had the greatest influence on safety dimension. Competence and expertise of people responsible for maintaining the infrastructure had the greatest influence on empathy dimension. While infrastructure maintenance had the greatest influence on reliability dimension and infrastructure capacity, in meeting current future demands had the greatest influence on responsiveness dimension.

Overall, Ajman residents' satisfaction on infrastructure reached $90 \%$, which is $14 \%$ higher than last year's overall satisfaction average. The same as last year, the residents strongly claimed that their dissatisfaction with paid utilities such as electricity, water, sanitation, transport, telecoms, is not satisfactory. Aside from this, residents were concerned about rain control infrastructures such as drainage, seawall, and dikes. Both elements were the least satisfactory last year as well. These need attention, first to the local government and then to the respective authority which can review and revisit current policy regarding cost of paid utilities and drainage infrastructure.

\section{Conflicts of Interest}

The authors declare no conflicts of interest regarding the publication of this paper.

\section{References}

Aliu Momoh, M. (2018). Infrastructure Classification Revisited. Journal of Social Science Research, 12, 2642-2652. https://doi.org/10.24297/jssr.v12i1.7277

American Society of Civil Engineers (ASCE) (2017). Infrastructure Report Card: A Comprehensive Assessment of America's Infrastructure. https://www.infrastructurereportcard.org

Bechger, T. M., van den Wittenboer, G., Hox, J. J., \& De Glopper, C. (1999) The Validity of Comparative Educational Studies. Educational Measurement: Issues and Practice, 18, 18-26. https://doi.org/10.1111/j.1745-3992.1999.tb00269.x

Bitre (2017) Australian Government, Department of Infrastructure, Transport, Regional Development and Local government. Bureau of Infrastructure, Transport and Regional Economics.

Buhr, W. (2003). What Is Infrastructure? Discussion Paper No. 107-03, Department of Economics School of Economic Disciplines University of Siegen. 
Cronbach, L. J. (1951). Coefficient Alpha and the Internal Structure of Tests. Psychometrika, 16, 297-334. https://doi.org/10.1007/BF02310555

Esfahani, S. (2005). Measuring Public Sector Performance in Infrastructure.

Hair Jr, J. F., Wolfinbarger, M., Money, A. H., Samouel, P., \& Page, M. J. (2015). Essentials of Business Research Methods. Routledge. https://doi.org/10.4324/9781315704562

Hirsshhausen, C. (1966). Modernizing Infrastructure in Transformation Economies: Paving the Way to European Enlargement. Berlin University of Technology.

Kunicova, J. (2018). The Five Drivers for Improving Public Sector Performance: Lessons from the New World Bank Global Report. World Bank Blogs.

OECD (Organisation for Economic Co-Operation and Development) (2004). OECD Principles of Corporate Governance. OECD Publications Service.

Oswald, M., Li, Q., McNeil, S., \& Trimbath, S. (2011). Measuring Infrastructure Performance: Development of a National Infrastructure Index. Public Works Management \& Policy, 16, 373-394. https://doi.org/10.1177/1087724X11410071

Torrisi, G. (2009). Public Infrastructure: Definition, Classification and Measurement Issues. Economics, Management, and Financial Markets, 4, 100-124.

World Bank (2005). Infrastructure and the World Bank: A Progress Report. World Bank. 